\title{
A filosofia enquanto cachimbo para duendes
}

\section{Philosophy as a smoking pipe for elves}

\author{
Junot Cornélio Matos \\ Orcid: https://orcid.org/0000-0002-0669-2066 - E-mail:junotcmatos@gmail.com \\ Sérgio Ricardo Vieira Ramos \\ Orcid: https://orcid.org/0000-0002-6972-0685 - E-mail: svramos@oi.com.br
}

\begin{abstract}
RESUMO
O texto problematiza o contexto de perseguição e negação do Ensino de Filosofia. Trata-se de uma tentativa de descredenciar a presença da Filosofia na Escola apresentando-a como um conhecimento inútil, sem nenhuma serventia para a formação do jovem estudante. No dizer de um integrante da corte governamental, "cachimbo para duendes". Os autores interpelam o que seria esse dito cujo "cachimbo" discutindo a importância da Filosofia e seu Ensino nos processos educacionais escolares; e, nesse sentido recoloca o papel crítico do filosofar e da Filosofia.
\end{abstract}

Palavras-chave: Filosofia. Criticidade. Ensino de Filosofia.

\begin{abstract}
The article problematizes the context of persecution and denial of the teaching process of philosophy. It is an attempt to discredit the presence of Philosophy in school by presenting it as useless knowledge, with no use for the training of the young student. In the words of a member of the government court, it can be referred as a "pipe for elves". The authors question what would be this "pipe" as manner of discussing the importance of Philosophy and its teaching in school educational processes; and, in this sense, it replaces the critical role of philosophizing and philosophy.
\end{abstract}

Keyword: Philosophy. Criticism. Philosophy teaching. 
A maioria do que eu me lembro dos primeiros anos é a minha própria ignorância terrível. Uma visão parcial do mundo foi entregue a mim... e o resto eu tive que fingir que sei. Como todas as crianças, eu era obrigada a cambalear de um reconhecimento com defeito para o outro, sempre prestes a tropeçar em vergonha. Não é o que nós sabemos, mas o que nós não sabemos que nos faz. Corando e desastrado, se embaralhando e gaguejando. Estas são expressões superficiais de uma dor mais profunda. A vergonha da ignorância está matando. (Carol Shields, Unless. A Novel, 2002. p. 142)

A imaginação corre solta quando o assunto ou questão é Filosofia inclusive porque, de per si, ela mesma a filosofia, é muito levada à imaginação. Ora, numa época em que os tons cinzentos da emissão de $\mathrm{CO} 2$ e seu kit necrófilo disputam hegemonia com o pensamento único das redes de notícia e de formação de opinião, que editam diuturnamente e estabelecem o que se deve ser, pensar, saber e escolher (desde a infância da razão até...), é muito auspicioso um respiradouro, quiçá um dispositivo humanitário, que preserve a humana condição de seu embotamento no vazio sem nada da falta ou da morte da imaginação. Realmente a experiência histórica de homens em tempos sombrios é um indicador de quanto é perigoso para uma cultura e uma criatura humana o potencial imaginativo deficitário.

Parece inerente à natureza humana a insubmissão ao posto. A indeterminação que trazemos como característica peculiar ao tempo em que induz a que vinculemo-nos às matrizes socioculturais que antecedem nossa gênesis, nos alavanca no espaço/tempo do impensado, do ainda não instaurado, de verdades em movimento e construção permanente

O que é a verdade, portanto? Um batalhão móvel de metáforas, metonímias, antropomorfismos, enfim, uma soma de relações humanas, que foram enfatizadas poética e retoricamente, transpostas, enfeitadas, e que, após longo uso, parecem a um povo sólidas, canônicas e obrigatórias: as verdades são ilusões, das quais se esqueceu que o são, metáforas que se tornaram gastas e sem força sensível, moedas que perderam sua efígie e agora só entram em consideração como metal, não mais como moedas. (SARTRE, 1992, p. 19).

Negar a possibilidade de mirar outra lógica que não as que se colocam à disposição, e pensar fora destas (ou seja, pensar fora da caixinha) configura-se em tempos milicianos em grave desrespeito às prévias definições do guardião universal que parece saber e poder definir o bem e o mau de cada um e de todos. A imaginação tem a força da insubordinação, de colocar a vontade em ação, de mover-se para algo muito além dos conceitos validados pelos dominantes das ideias e das classes. Pensar mais além porque fundado no que a vida deixa emergir, refletir sobre tais fenômenos, elaborar questões que perscrutam a própria razão instrumental fora dos ditames por ela convencionados apresenta-se como um perigo sério e uma ideologia perigosa. Homens e Mulheres são concebidos em série e em rebanho são chamados a adentrar no estreito recinto de seus modelitos. Há um zona que nos acolhe confortavelmente assegurando um céu sem trepidações, um dito que estabelece o cômodo, um dispositivo que pensa por nós, fala por a gente, antecipa-se à nossa ação... e nos leva a crer que tudo é nosso, que somos autores e atores do estabelecido, sem mesmo sabermos exatamente que coisa é essa.

Há um modo distorcido ou retorcido de imaginar e de julgar a imaginação. Concebê-la como vã filosofia. Atribuir para ela a sentença de "lugar nenhum" em oposição ao decantado "lugar neutro", relativizar a filosofia como uma viagem pueril, simplória, simplificada. No passado, filósofos eram taxados de gays, drogados, dementes. Junta-se a tudo isso a encomenda de vendedor de charutos para duendes ou propagador de sexo anal indolor. Poderia ser cômico se não estivesse atravessado de um ideário retrógrado e conservador. Caberia atenção se não fosse o somente o reflexo de um projeto histórico que intenta expurgar qualquer possibilidade de crítica. 
Desde Sócrates parece possível problematiza a utilidade da filosofia. Reza a lenda que a Filosofia é inútil. É uma masturbação mental da qual se ocupam os "desocupados". De fato, não se deve buscar na filosofia uma utilidade, ou uma serventia, mas a possibilidade de construção de sentidos. Ou seja, a filosofia não tem que ser útil, carece, sim, de sentido. É um processo do pensar que conduz à elaboração das perguntas da vida. Questões que varam o estabelecido. Indagações que desacomoda pois coloca como problema o próprio existir e suas diferentes configurações.

Mas a imaginação permanece um nada que é tudo, um salto da imanência, um lançar-se da existência singular do humano no mundo. Mundo que é produtor e produção, cuja consciência só é possível pela presença distanciada de homens e mulheres. Homens e mulheres que humanizam o mundo à medida que se humanizam.

Savater (2012; p. 29) reflete que"nascemos humanos, mas isso não basta: temos também que chegar a sê-lo". E diz mais: "A condição humana é em parte espontaneidade natural, mas também deliberação artificial: chegar a ser totalmente humano - seja humano bom ou humano mau - é sempre uma arte." (idem, p. 31). Assemelha-se a ideias de Kant que assentou no início do seu escrito Sobre a Pedagogia lê-se: "O homem é a única criatura que precisa ser educada. Por educação entende-se o cuidado de sua infância (a conservação, o trato), a disciplina e a instrução com a formação." (KANT, 2006, p. 11). Mais à frente diz: "O homem não pode tornar-se um verdadeiro homem senão pela educação. Ele é aquilo que a educação dele faz." (KANT, 1996, p. 15). Nessa direção parece pertinente propor a Filosofia como mediação de formação humana e indicar sua direta relação com a educação.

É frequente dizer-se que educação é processo de formação humana. Um processo de constituição da humanidade dos humanos? Ou um processo de constituição da humanidade nos humanos? Se a primeira, a humanidade dos humanos é construída na própria prática humana do existir; se a segunda haveria uma humanidade a ser realizada em cada ser humano. Estas questões trazem ainda outra: o que é mesmo ser humano? O que é mesmo humanidade? E, por certo, daí decorrente, outra: seres humanos devem ser formados? Devem ser constituídos como tais? Se sim, em que consiste o processo de sua formação? Há uma profunda relação da Filosófica com a Educação. Negar a homens e mulheres a possibilidade de se entenderem, dizerem de si, entenderem os fenômenos que lhe cercam, os tempos/espaços que lhe albergam, é negar sua própria humanização.

A afirmação de que a Ensinar Filosofia é vender cachimbo para duendes nos permite pensar uma fenomenologia do cachimbo do duende, tentando categorizar os dois termos para melhor entendimento:

1) Duendes - pode implicar em deslocamento, estranhamentos e enraizamentos;

2) Cachimbos com a representação de tradição, Cachimbo da paz - sobre violência, ética e política, lazer: Cachimbando a vida.

Tais considerações parecem tornar possível desenvolver uma Poética e uma Pedagógica do cachimbo de duende e propor a Filosofia como parceria e compartilhamento. Nesse caso, pensamos que o duende, como imagem de algo muito além do dito, subverte a ordem desvelando mundo outros, quem sabe a tal "terceira margem", à qual se referia Rosas. O cachimbo, a elevação do si mesmo na contemplação explícita e no compartilhamento entre convivas.

Refletir sobre a presença da Filosofia no cotidiano da escola permite a elaboração de algumas questões preliminares cujo escopo é, diretamente, desmistificar quaisquer pretextos de leituras parciais ou resposta de ocasião. Necessário expressar que não nos dividimos entre 
o pessimismo da razão e o otimismo da vontade, nem advogamos ser possível creditar à realidade a forças ocultas que lhe são exteriores, ou, aos seus condicionamentos intrínsecos. O cotidiano está sendo produzido socialmente. Condicionado, tanto por fatores extrínsecos, quanto, por elementos internos. Sempre que pensamos o trabalho pedagógico do professor de filosofia na escola somos tomados pelo estranhamento do que representa sua presença disciplinarizada, creditada como componente curricular, e, embora reconheça mérito em todo o esforço que se tem empreendido no sentido de formatar e disponibilizar ferramentas pedagógicas mais adequadas ao seu ensino, damo-nos o privilégio da dúvida: Será mesmo esse o lugar de sua presença?

O que desejam, aqueles que jocosamente atribuem ao filósofo o mister de vender cachimbo para duendes é um pensar um trabalho pedagógico com a Filosofia isento dos condicionamentos do entorno da escola. Como exercício de abstrata doutrinação na qual não são os verdadeiros protagonistas que estão definindo os cenários escolares, mas os ditames de agências financiadoras internacionais. Chegam a chamar isso de "escola sem partido". Isso, porquê

A Filosofia, se não pode responder a tantas perguntas como gostaríamos, tem pelo menos o poder de fazer perguntas que aumentam o interesse do mundo, e mostram a estranheza e a maravilha repousando imediatamente sob a superfície mesmo nas coisas mais comuns da vida cotidiana (RUSSELL, 2008, p. 78).

Estudantes inquietos e curiosos a respeito de si mesmos, do que estão sendo e do que poderão vir a ser, do mundo que lhes alberga e do tempo/espaço em que existem são, por vezes, ignorados em sua concretude em benefício de nosso bem intencionado abecederário filosófico. Quem são eles? Quais suas experienciais vitais de existências? Parece que cabe ao professor a definição prévia daquilo que eles podem e devem aprender. Tudo isso para dar conta de determinações que são anteriores à própria escola.

Quando focada na escola básica é outra a tarefa da atividade filosófica. Nessa, a filosofia é instada a realizar sua dimensão de formação para a vida. Aqui a filosofia é chamada a ser praticada como educação; ou seja, processo contínuo de formação da pessoa humana em sua concretude e singularidade. Outro aspecto a ser considerado quando discutimos a presença da filosofia como componente curricular da escola é que ao contrário das demais disciplinas curriculares que parece bastarem-se em assegurar estratégias e mediações técnicas para a transmissão de um saber já constituído, ela precisa afirmar-se como uma atitude, uma busca desejante e corajosa. "A aposta consiste em encontrar que se possa ensinar algo próprio à atividade filosófica em si", afirma Cerletti (2004, p. 27).

Nossa defesa da filosofia enquanto mediação inquiridora das realidades apoia-se no postulado de que questões filosóficas que são aquelas que todos os seres humanos se fazem e de cujas respostas se servem para orientar sua forma de ser gente, sua forma de agir, sua forma de pensar, sua forma de valorar, sua forma de organizar a vida social. Dizem respeito: à realidade em geral, ao seu ser, a seu possível sentido (ontologia); ao ser humano e ao sentido de sua existência, (antropologia filosófica); ao agir humano, ao justo, ao bom, ao certo (ética); ao pensar e produzir conhecimentos (teoria do conhecimento); ao fato de os seres humanos viverem em sociedade, ao poder e à liberdade (campo da filosofia social e política); ao belo, à beleza, à sua busca e produção-representação pelos homens (campo da estética); ao nosso processo de argumentação-raciocínio (lógica); e 76 tantas outras questões como as referentes à linguagem, à história, à educação.

Esse processo de dizer algo de si para si e sobre si, de perguntar pela forma determinada como estamos vivendo e porque a vivemos, de tecer-se numa tensa relação com o outros que é simultaneamente um fora de si e um si-mesmo, esse movimento de perceber-se num mundo 
que é chão de possibilidade e plataforma de construção parece implicar num desafio importante para o trabalho com a filosofia na escola. Nossas convicções são entendidas como limitadas e provisórias, mas, escoramos nossa ousadia em Nietzsche quando segreda "não nos deixaríamos queimar por nossas opiniões: não estamos tão seguros delas. Mas, talvez, por podermos ter nossas opiniões e podermos mudá-las." (1995, p. 12)

A questão da presença da Filosofia como no Ensino Médio levanta inúmeras polêmicas embora exista consenso quanto à sua importância na formação cultural de adolescentes e jovens no momento em que buscam respostas fundamentais para as escolhas que deverão fazer na construção de seu projeto de vida. Tal importância encontra amparo em Navia (2005, p. 277278) quando ressalta:

[...] não há nenhuma outra instância onde se reflete sobre o fundamento e os limites do conhecimento, tratando de gerar critérios sobre a distinção entre conhecimento fundamentado e não fundamentado e de tirar fora o obscurantismo e a mistificação da ciência; não há outro âmbito onde se reflete sobre problemas éticos, estéticos, antropológicos, sócio-históricos e culturais, procurando um antídoto contra o dogmatismo, o fanatismo e a intolerância. Uma instância, além disso, onde se desenvolve as capacidades de argumentação e discussão de ideias explicitamente fundamentadas e com elucidação dos princípios supostos implicados como modelo privilegiado de qualquer análise, elucidação, e avaliação que inclua princípios gerais.

Entretanto, talvez por isso mesmo ela encontra-se tão achincalhada por aqueles que temem a democracia e o direito à divergência e à crítica. Pode até ser que essa seja a "grande viagem" promovida pelos que negociam cachimbos: a recusa à subserviência, a superação do embrutecimento da consciência, a capacidade do estranhamento para a ousadia de despontam o novo e como novo.

Finalmente, devemos assinalar que o Ensino de Filosofia em sua presença na escola não pode e não deve passar sem que nós, educadores e educando no campo da filosofia, nos apercebamos de sua complexidade, da armadilha que ele pode representar para nós, mas, também, das possibilidades que ele oportuniza. Entretanto, o trabalho não é somente lá, no terreno arenoso da escola de ensino fundamental e médio. Ele começa entre nós e nossa responsabilidade não pode ser delegada para pessoas que contam com boa vontade, conhecimento e experiência de docência, mas não conta com uma formação específica. Por isso o desafio é político, no sentido que trata-se não somente de mais uma disciplina no chão da escola, mas do projeto político republicano e democrático e seus requerimentos de participação, é transdisciplinar; o desafio é, igualmente, pedagógico, pois requer paciência e esforço de diálogo, requer disposição para inventar e formatar outro modelo de ensinagem/aprendizagem, Exige de nós a convicção de que pensar em educação "significa pensar, necessariamente, no homem e na sociedade, tanto do ponto de vista filosófico como político". Cerisara (2001. p. 170). Bauman (1999, p. 11) escreveu que "Questionar as premissas supostamente inquestionáveis do nosso modo de vida é provavelmente o serviço mais urgente que devemos prestar a nossos companheiros humanos e a nós mesmos".

\section{Referências bibliográficas}

CERLETTI, Alejandro. Ensinar Filosofia: da pergunta filosófica à proposta metodológica. In Kohan, Walter O. (Org.) Filosofia: caminhos para seu ensino. Rio de Janeiro. DP\&A, 2004.

KANT, Immanuel. Sobre a Pedagogia. Tradução Francisco C. Fontanella. Piracicaba-SP: Editora Unimep, 2006. 
NAVIA, Ricardo. O ensino médio de filosofia nas presentes condições culturais e sociais de nossos países. In. Filosofia e ensino: a filosofia na escola, p. 278-290.

NIETZSCHE, Friedrich. Ecce Homo. Wie man wird was man ist. Vol. II, 1955. [Ecce Homo. Como cheguei a ser o que sou] Tradução de Lourival de Queiroz Henkel. Edições de Ouro.

RUSSELL, Bertrand. Os problemas da Filosofia. Trad. de Desidério Murcho. Lisboa: Edições 70, 2008.

SARTRE, Jean-Paul. O Imaginário. Trad. Duda Machado. São Paulo: Ed. Ática, 1992.

SAVATER, Fernando. O valor de educar. Trad. de Monica Stahel. São Paulo: Planeta, 2012.

SHIELDS, C. Unless. A novel. New York: Harper Collins, 2002.

\section{Sobre os autores}

\section{Junot Cornélio Matos}

Doutor em Educação, Professor Associado II da Universidade Federal de Pernambuco. Coordenador do Mestrado Profissional em Filosofia. Pesquisa os temas de Filosofia e Educação, Formação de Professores de Filosofia, Ensino de Filosofia, Filosofia de Nietzsche. Além disso, está integrado em estudos e debates sobre temas, como: Fundamentos da Educação em Direitos Humanos, Pensamento pedagógico de Paulo Freire.

\section{Sérgio Ricardo Viera Ramos}

Doutor em Filosofia pela Universidade Federal de Minas Gerais(2008). Docente da Universidade Federal de Pernambuco. Vice-coordenador do Mestrado Profissional em Filosofia. Tem experiência na área de Filosofia, com ênfase em Ética. 